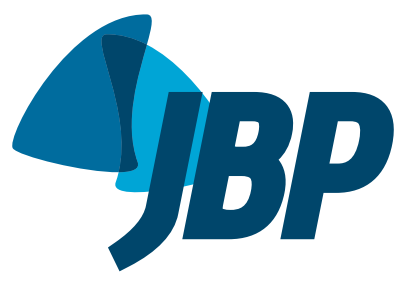

\title{
Robotic thoracic surgery for resection of thymoma and tumors of the thymus: technical development and initial experience
}

\author{
Ricardo Mingarini Terra ${ }^{1, a}$, José Ribas Milanez-de-Campos", ${ }^{1, b}$ Rui Haddad ${ }^{2, c}$, \\ Juliana Rocha Mol Trindade ${ }^{3, d}$, Leticia Leone Lauricella, \\ Benoit Jacques Bibas ${ }^{3, f}$, Paulo Manuel Pêgo-Fernandes ${ }^{1,9}$
}

1. Disciplina de Cirurgia Torácica, Instituto do Coração, Faculdade de Medicina Universidade de São Paulo, São Paulo (SP) Brasil.

2. Disciplina de Cirurgia Torácica, Universidade Federal do Rio de Janeiro, Rio de Janeiro (RJ) Brasil.

3. Instituto do Câncer do Estado de São Paulo - ICESP - Hospital das Clínicas, Faculdade de Medicina, Universidade de São Paulo, São Paulo (SP) Brasil.

a. (ID) http://orcid.org/0000-0001-8577-8708

b. (iD) http://orcid.org/0000-0002-2385-7707

c. (iD http://orcid.org/0000-0002-1288-3539

d. (ID) http://orcid.org/0000-0002-8190-8410

e. (iD) http://orcid.org/0000-0002-8378-7704

f. (D) http://orcid.org/0000-0002-5092-0505

g. (D) http://orcid.org/0000-0001-7243-5343

Submitted: 28 October 2018

Accepted: 20 April 2019

\begin{abstract}
Objective: To evaluate the results of resection of tumors of the thymus by robotic thoracic surgery, analyzing the extent of resection, postoperative complications, time of surgery, and length of stay. Methods: Retrospective study from a database involving patients diagnosed with a tumor of the thymus and undergoing robotic thoracic surgery at one of seven hospitals in Brazil between October of 2015 and June of 2018. Results: During the study period, there were 18 cases of resection of tumors of the thymus: thymoma, in 12; carcinoma, in 2; and carcinoid tumor, in 1; high-grade sarcoma, in 1; teratoma, in 1; and thymolipoma, in 1 . The mean lesion size was $60.1 \pm 32.0 \mathrm{~mm}$. Tumors of the thymus were resected with tumor-free margins in 17 cases. The median (interquartile range) for pleural drain time and hospital stay, in days, was 1 (1-3) and 2 (2-4), respectively. There was no need for surgical conversion, and there were no major complications. Conclusions: Robotic thoracic surgery for resection of tumors of the thymus has been shown to be feasible and safe, with a low risk of complications and with postoperative outcomes comparable to those of other techniques.
\end{abstract}

Keywords: Thymoma; Thymus neoplasms; Thymectomy; Thoracic surgery; Robotic surgical procedures.

Study carried out in the Disciplina de Cirurgia Torácica, Instituto do Coração,

Faculdade de Medicina, Universidade de São Paulo, São Paulo (SP) Brasil.

\section{INTRODUCTION}

Thymomas and other tumors of the thymus are relatively rare neoplasms. Their treatment usually involves resection of the thymus and adjacent mediastinal fat. They are associated with paraneoplastic syndromes, the most common being myasthenia gravis, which is present in approximately one third of patients with thymoma. ${ }^{(1)}$ Surgical treatment is indicated for the treatment of stage I and II thymomas, with a 10-year survival rate of $70-90 \%$. (2) In more advanced stages and in cases of tumor recurrence, surgical resection, in combination with chemoradiotherapy, is indicated for local control of the disease. ${ }^{(3,4)}$

In the 1990s, the concept of minimally invasive surgery was introduced into the field of thoracic surgery and began to be applied in mediastinal surgical resections. The use of minimally invasive thymectomy was motivated by the possibility of minimizing the deleterious effects of prolonged general anesthesia and the postoperative pain caused by thoracotomy in patients with myasthenia gravis. In this context, studies have proven total thymectomy by video-assisted thoracoscopic surgery to be feasible in patients with myasthenia gravis ${ }^{(5)}$ and also for those with stage I and II thymomas. ${ }^{(6)}$ Since the beginning of the 21st century, robotic surgery has emerged as an interesting alternative because it not only offers the advantages of being minimally invasive but also provides a wider range of motion to the surgical performance, reduces the impact of surgeon hand tremors, enables greater precision in the movement of the forceps, and provides better three-dimensional visualization of the surgical field. ${ }^{(7,8)}$

In Latin America, especially in Brazil, minimally invasive thoracic surgery has recently come to be more widely used. ${ }^{(9)}$ However, in contrast to the literature on pulmonary resections, ${ }^{(10)}$ there is a lack of studies describing the results of resection of thymic tumors by robotic surgery. The primary objective of the present study was to evaluate the results of the resection of thymic tumors with the aid of robotics by determining the extent of resection, postoperative complications, operative time, and length of hospital stay.

\section{METHODS}

This was a retrospective study of patients diagnosed with a thymic tumor who underwent resection by robotic

Correspondence to:

Ricardo Mingarini Terra. Instituto do Coração, Hospital das Clínicas, FMUSP, Avenida Dr. Enéas de Carvalho Aguiar, 44, Bloco 2, $2^{\circ}$ andar, Sala 9 , Cerqueira Cezar, CEP 05403-000, São Paulo, SP, Brasil.

Tel.: 5511 2661-5708. E-mail: rmterra@uol.com.br

Financial support: None. 
thoracic surgery. Every procedure was performed by the same group of surgeons, at one of seven hospitals in Brazil, and the lead author participated in all of them, either as the surgeon operating the console or as the proctor. The robotic platform used was the da Vinci Intuitive Surgical System (Intuitive Surgical Inc., Sunnyvale, CA, USA). The hospitals involved were the São Paulo State Cancer Institute, Hospital Sírio-Libanês, Hospital Albert Einstein, Hospital Nove de Julho, and Hospital São Luiz, all located in the city of São Paulo, as well as the Hospital Copa Star and Hospital Quinta D'Or, both located in the city of Rio de Janeiro. All of the surgical procedures were performed between October of 2015 and June of 2018.

Data were collected from a database dedicated to robotic surgery and maintained by our team of thoracic surgeons. We included all cases of thymic tumors treated surgically during the period and excluded only patients whose medical records did not present information regarding sociodemographic data and histological type. Our eligibility criteria for robotic resection of mediastinal tumors were as follows: the patient being considered a candidate for the proposed procedure, on the basis of the clinical and anesthetic evaluation; the tumor being in the thymus; and there being no signs of invasion of adjacent structures such as the heart and great vessels. Tumor invasion of the pericardium or lung was not considered a contraindication to the robotic procedure. Figure 1 shows HRCT images of 2 patients with thymic tumors.

The surgical technique used was based on the description provided in a study conducted by Rueckert et al. ${ }^{(10)}$ When that technique is employed, access to the mediastinum is preferentially through the left side of the chest (Figures 2 and 3). However, in some cases, the position of the tumor may necessitate right-sided access. The patient is placed in the supine position with the head rotated $30^{\circ}$ to the contralateral side. Three surgical incisions are made for the ports, which are used for the robotic arms (one for the three-dimensional vision and two for the robotic forceps) positioned in the 3rd, 4th and 5th intercostal spaces (Figure 2). We also use an additional port for the assistant surgeon, who remains with the patient during surgery.

The surgery begins with the identification of the left phrenic nerve (Figure $3 \mathrm{~A}$ ) and subsequent opening of the mediastinal pleura anterior to it. Subsequently, loose connective tissue adjacent to the lesion is dissected until the mediastinal structures such as the pericardium, aorta, and innominate vein are completely exposed (Figure 3B). Complete resection of the thymus or resection of only the thymic tumor may then be performed. ${ }^{(11)}$

The variables evaluated in the present study were related to the surgical technique (operative time and partial or complete thymic tissue resection), perioperative outcomes (length of ICU stay, length of hospital stay, duration of pleural drainage, and postoperative complications), and the extent of the resection.
Total operative time was defined as the time from the initial incision to the final closure, including the creation of the ports, robot docking, console operation, and chest wall closure. The drainage time, length of ICU stay, and length of hospital stay were measured in days from the day of surgery, which was designated (D0), the subsequent days being designated D1, D2, etc. The discharge date was defined as the day on which the patient left the hospital, regardless of the time of discharge.

The extent of surgical resection was assessed by review of the pathology report. If the surgical specimens showed tumor-free margins or margins coincident with structures that precluded further resection, such as the sternum, pleural surface, or pericardium, the resection was categorized as curative (R0).(12) The thymomas were staged according to the Masaoka-Koga classification. $^{(13)}$

\section{Statistical analysis}

Continuous variables are expressed as mean and standard deviation or as median and interquartile range (IQR). Categorical variables are expressed as absolute and relative frequencies. Type I error was set at $5 \%$.

\section{RESULTS}

During the study period (from October of 2015 to June of 2018), 243 robotic procedures were performed by our group. Of those, 52 were resections of mediastinal lesions, including 33 of the anterior mediastinum, of which 18 were primary tumors of the thymus.

Of the patients with thymic tumors, half were male, and the mean age of the patients was $47.0 \pm 12.1$ years. The histological types found are described in Table 1. The mean size of the lesions, according to the pathology reports, was $60.1 \pm 32.0 \mathrm{~mm}$.

The surgical technique employed was that described by Rueckert et al., ${ }^{(10)}$ which utilizes three robotic arms and a secondary access for the auxiliary port. In the original technique, the preferential approach to the mediastinum is from the left side. However, in 6 of our cases, the location of the tumor dictated that the access be from the right side, and the robot was therefore positioned on that side. Total thymectomy associated with tumor resection was performed in 9 patients. The median total operative time and console time were $130 \mathrm{~min}$ (IQR: $90-156 \mathrm{~min}$ ) and $72 \mathrm{~min}$ (IQR: 52.5-102.5 min), respectively. No significant intraoperative accidents were observed, nor was it necessary to convert to video-assisted surgery or open surgery in any of the cases.

Postoperatively, patients were hospitalized for 2-4 days (median $=2$ days). Surgical recovery was in the ICU in 6 cases, the mean length of ICU stay being 1.1 days. Drainage time ranged from 1-3 days (median = 1 day).

The only early complication observed in our study was elevation of the hemidiaphragm, in 2 cases 


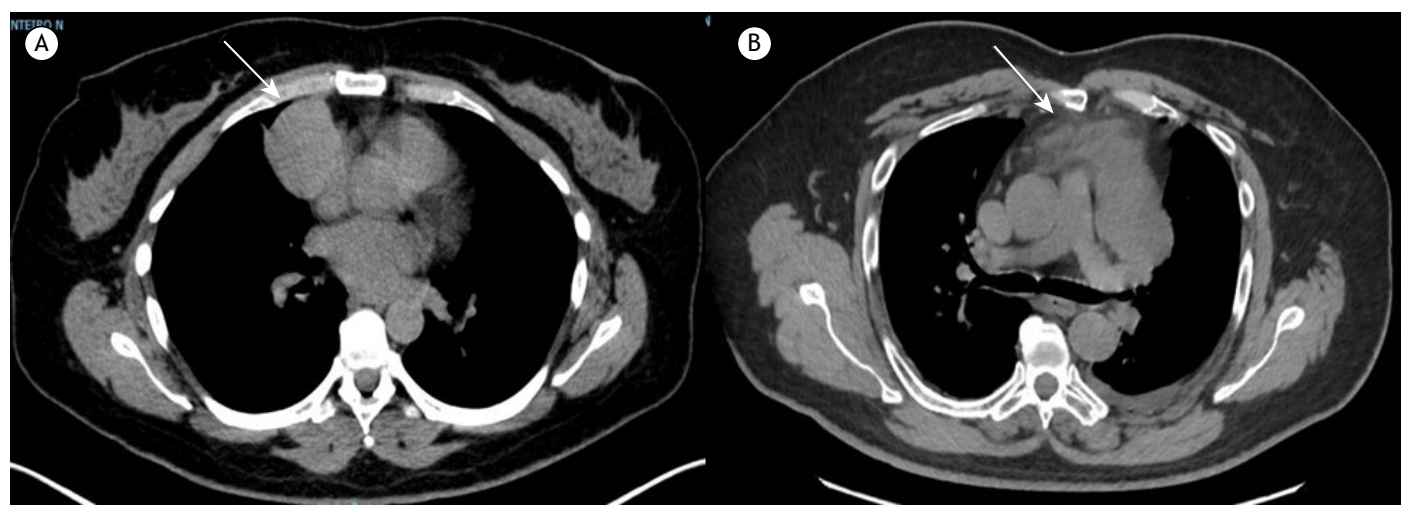

Figure 1. Chest HRCT. In A, a 47-year-old female patient with a history of papillary thyroid carcinoma (18 years earlier) and a right paracardiac mediastinal mass of $54 \mathrm{~mm}$. Histological diagnosis of B1/B2 thymoma, Masaoka-Koga stage I classification. In B, a 59-year-old male patient with a left anterior mediastinal mass of $82 \mathrm{~mm}$. Histological diagnosis of high-grade thymic sarcoma.

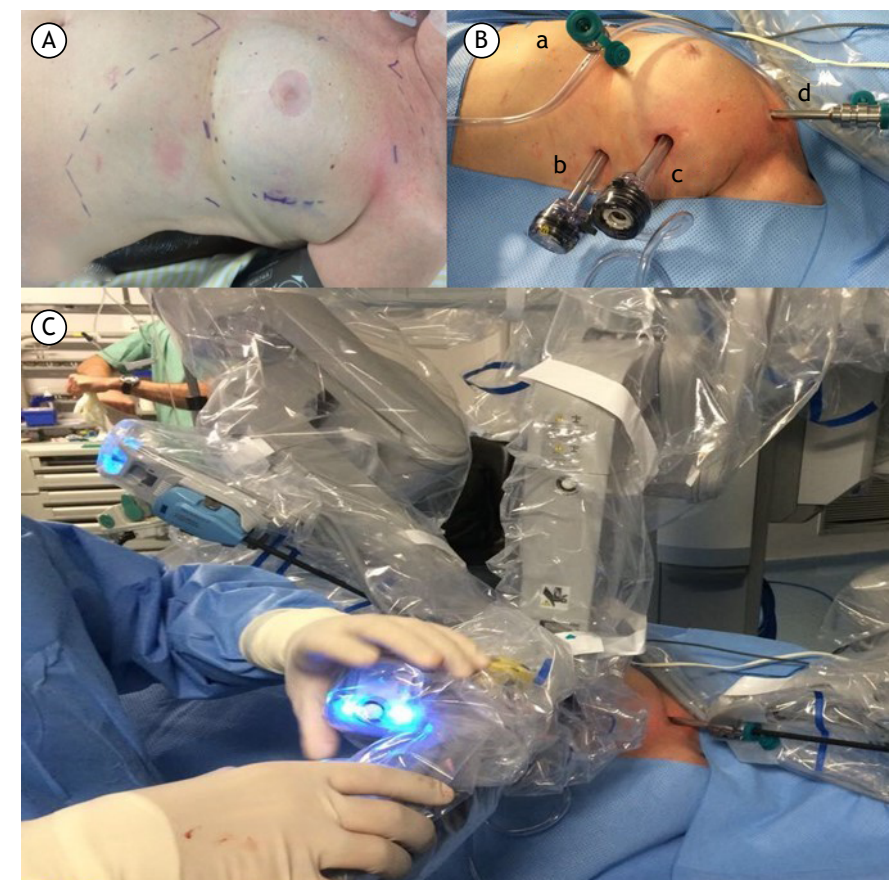

Figure 2. Positions of the robotic ports. In $A$, preoperative demarcation of the costal spaces and incision sites. In $B$, surgical ports before robot docking ( $a$, arm $1 ; b$, auxiliary port; $c$, camera; and d, arm 2). In C, robotic arms coupled to ports after docking.

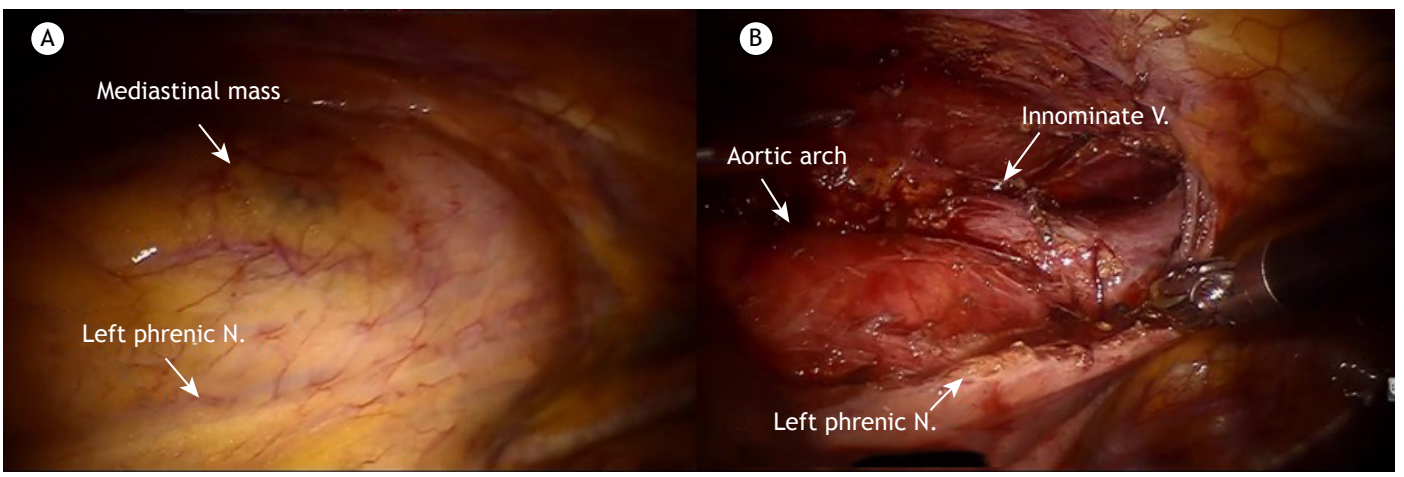

Figure 3. Endoscopic images. In A, initial endoscopic view, with mediastinum and tumor covered by the mediastinal pleura, identifying the left phrenic nerve in advance of the opening of the pleura and beginning of the dissection. In $B$, the surgical site after thymectomy and thymoma resection, with the mediastinal structures being visualized. $N$.: nerve; and V.: vein. 
Table 1. Histological types of thymic tumors, operative times and postoperative data.

\begin{tabular}{|c|c|c|c|c|c|c|c|c|c|}
\hline \multirow[b]{2}{*}{$\begin{array}{l}\text { Histological } \\
\text { type }\end{array}$} & \multirow[b]{2}{*}{ Cases } & \multicolumn{6}{|c|}{ Thymic tumors resected by robotic thoracic surgery } & \multirow[b]{2}{*}{$\begin{array}{l}\text { Drainage } \\
\text { time, } \\
\text { days }\end{array}$} & \multirow[b]{2}{*}{$\begin{array}{l}\text { Length of } \\
\text { hospital } \\
\text { stay, days }\end{array}$} \\
\hline & & $\begin{array}{l}\text { Case } \\
\text { No. }\end{array}$ & Histology & $\begin{array}{c}\text { Masaoka- } \\
\text { Koga } \\
\text { Classification }\end{array}$ & $\begin{array}{l}\text { Size, } \\
\mathrm{mm}\end{array}$ & $\begin{array}{c}\text { Total } \\
\text { operative } \\
\text { time, min }\end{array}$ & $\begin{array}{c}\text { Console } \\
\text { time, } \\
\text { min }\end{array}$ & & \\
\hline \multirow{12}{*}{ Thymoma } & \multirow{12}{*}{12} & 17 & $A B$ & Ila & 76 & 80 & & 1 & 2 \\
\hline & & 20 & B1 & I & 30 & & & 1 & 2 \\
\hline & & 82 & $\begin{array}{l}\text { B1 }(70 \%) \\
\text { B2 }(30 \%)\end{array}$ & I & 54 & 140 & 90 & 1 & 2 \\
\hline & & 83 & & & 8,5 & 235 & 200 & 2 & 4 \\
\hline & & 138 & B2 & I & 50 & 110 & 85 & 1 & 3 \\
\hline & & 159 & $A B$ & Ila & 40 & 100 & 59 & 1 & 2 \\
\hline & & 180 & B2 & $\mathrm{IVa}$ & 84 & & & 3 & 4 \\
\hline & & 185 & $A B$ & I & 61 & 79 & 47 & 1 & 3 \\
\hline & & 187 & B2 & I & 53 & & & 2 & 4 \\
\hline & & 190 & B2 & Ila & 90 & 135 & 100 & 1 & 2 \\
\hline & & 221 & $A B$ & Ila & 100 & 140 & 100 & 1 & 2 \\
\hline & & 237 & $A B$ & I & 17 & 75 & 30 & 1 & 2 \\
\hline \multirow{2}{*}{$\begin{array}{c}\text { Thymic } \\
\text { carcinoma }\end{array}$} & \multirow{2}{*}{2} & 116 & & & 17 & 100 & 60 & 1 & 2 \\
\hline & & 153 & & & 90 & 85 & 55 & 1 & 2 \\
\hline $\begin{array}{l}\text { Thymic } \\
\text { carcinoid } \\
\text { tumor }\end{array}$ & 1 & 160 & & & 20 & 94 & 77 & 1 & 2 \\
\hline $\begin{array}{l}\text { High-grade } \\
\text { thymic } \\
\text { sarcoma }\end{array}$ & 1 & 172 & & & 82 & 260 & 210 & 2 & 3 \\
\hline $\begin{array}{l}\text { Mature } \\
\text { thymic } \\
\text { teratoma }\end{array}$ & 1 & 228 & & & 85 & 90 & 50 & 1 & 2 \\
\hline Thymolipoma & 1 & 240 & & & 125 & 130 & 70 & 1 & 2 \\
\hline
\end{tabular}

$(11 \%)$. However, it had no clinical repercussions for the affected patients. One patient required readmission due to chylothorax diagnosed one month after surgery and was treated by thoracic duct embolization. There were no deaths in the present study.

Among all the resected tumors, compromised margins were described in the pathology report in only 1 case $(5 \%)$, which was in a patient with thymoma. In that case, the margin was focally coincident with the area of the encapsulated neoplasm. Therefore, after a multidisciplinary discussion, the decision was made to administer adjuvant radiotherapy. The patient with a thymic carcinoid tumor presented signs of locoregional recurrence three months after surgery and underwent systemic treatment. At this writing, the patient was awaiting additional local treatment with surgery or radiotherapy. Lymph nodes were resected from at least one lymph node chain in 7 patients (mean, 3.4 lymph nodes/patient).

Of the 12 thymomas evaluated, 11 were categorized in the pathology examinations according to the Masaoka-Koga classification ${ }^{(13)}$, as follows: stage I, in 6 ; stage IIa, in 4; and stage IVa, in 1 . The patient with stage IVa thymoma was diagnosed intraoperatively with an anterior mediastinal tumor (Figure 4) and therefore underwent two surgical procedures. The first procedure was aborted after the identification of pleural implants and positive frozen section analysis results for neoplasia, after which the patient was submitted to neoadjuvant chemotherapy, resulting in a partial tumor response. The second procedure was performed four months later for complete resection of the thymoma, which presented local invasion of the lung and pleura.

In our sample, 4 patients received multimodal treatment and neoadjuvant chemotherapy. Of those 4 patients, 3 were diagnosed with thymoma and 1 was diagnosed with thymic carcinoma. Another patient received adjuvant radiotherapy after thymoma resection.

\section{DISCUSSION}

We have shown that the resection of thymic tumors by robotic surgery is feasible and safe. The implementation of a surgical technique in daily practice is a challenge, because the expectation is to achieve results comparable to those of medical centers where the technique is already well-established, although the experience of a team is based on its learning curve. Like our group, others have published their experiences with robotic surgery, reporting similar results. ${ }^{(14,15)}$

At the beginning of their robotic surgery program, Brown et al. ${ }^{(16)}$ considered thymectomy to be the surgery of choice, because of the location of the thymus in the anterior mediastinum. Nevertheless, only 5 (10\%) 


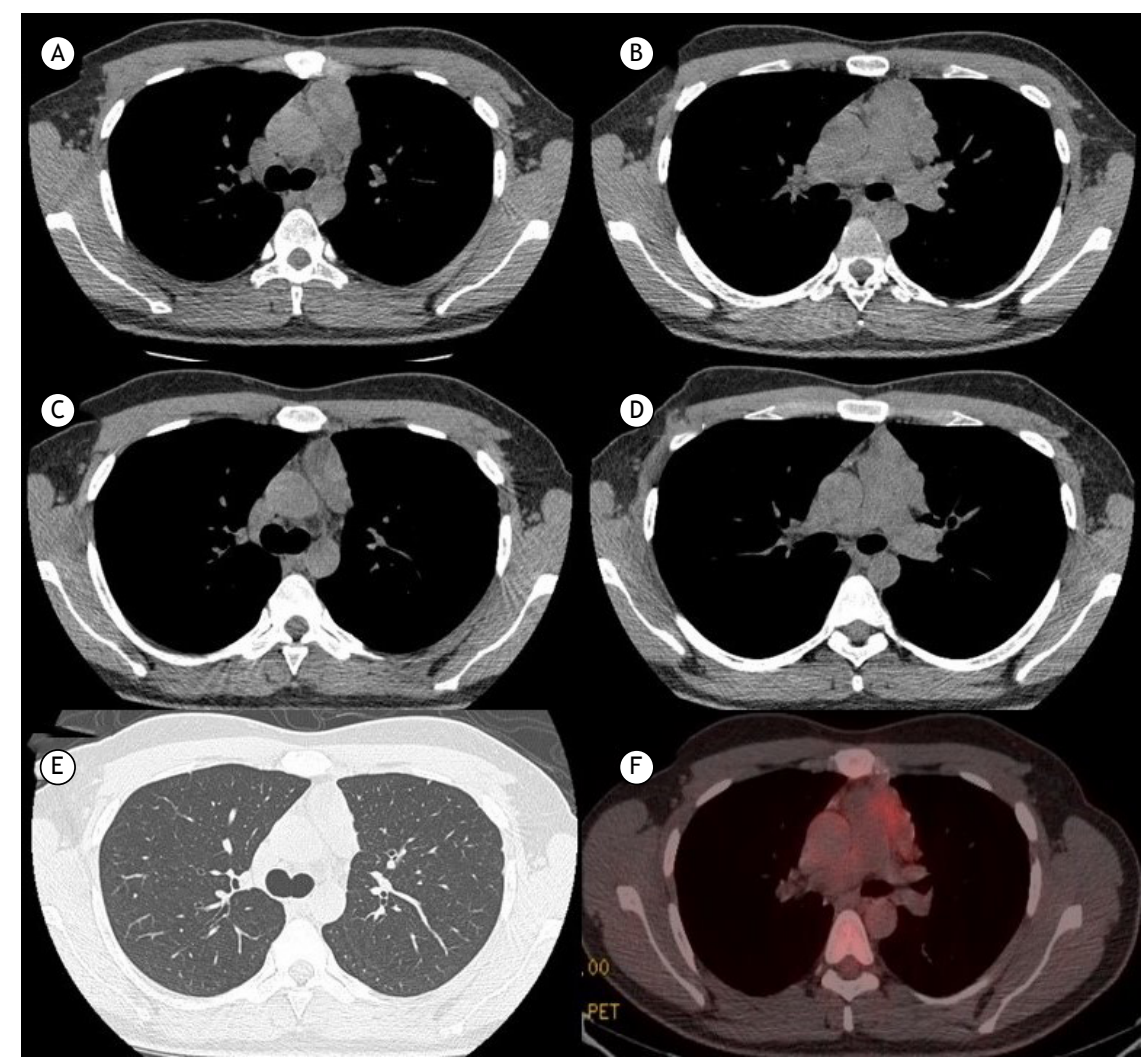

Figure 4. HRCT (A-E) and proton emission CT images ( $F$ ) of the chest. In $A$ and $B$, images of the thymoma in the initial preoperative evaluation. In $C, D$ and $E$, images after neoadjuvant chemotherapy. In $F$, image of the thymoma after neoadjuvant treatment.

of our first 50 procedures were performed for the resection of mediastinal lesions. That is explained by the fact that our robotic thoracic surgery program was initially implemented at the São Paulo State Cancer Institute, where a prospective study was conducted to draw comparisons between pulmonary lobectomy performed by video-assisted thoracic surgery and pulmonary lobectomy performed by robotic thoracic surgery, ${ }^{(17)}$ during which the surgeons in our group obtained their initial training and experience. That may have contributed to the fact that our operative time and perioperative outcomes were consistent with those reported by other groups with more experience in robotic surgery of the mediastinum. ${ }^{(18,19)}$

Following current trends, a systematic review published in $2018^{(20)}$ proposed that minimally invasive surgery, including video-assisted thoracic surgery and robotic thoracic surgery, should be considered the surgical technique of choice in the treatment of earlystage thymic tumors. Minimally invasive treatment is associated with shorter hospital stays, less intraoperative bleeding, and better aesthetic results. In the present study, we showed that robotic surgery is associated with a shorter duration of pleural drainage and a shorter hospital stay, with medians of 1 and 2 days, respectively. In addition, minimally invasive surgery has been shown to be as effective as open surgery in terms of the rates of complications, local recurrence, and survival.(20) In the present study, the follow-up period was too short to allow us to estimate cancer outcomes. However, the low risk of complications was confirmed, given that only one complication (late chylothorax) was observed and none of the patients required reoperation.

As evidenced in studies on complications after mediastinal lymphadenectomy, chylothorax after thoracic surgery presents a good response to conservative treatment or embolization because it is a chylous fistula resulting from thoracic duct collaterals, ${ }^{(21)}$ that is, of low output.

Regardless of the access route, the importance of complete tumor resection in terms of prognosis is known ${ }^{(22)}$; as such, all efforts should be directed to the total resection of the tumor and surrounding thymic tissue by avoiding direct manipulation to prevent capsule rupture and the spread of the tumor in the location. In our study, only 1 case did not present tumor-free margins after histopathological analysis, which was focally coincident with the encapsulated area of the tumor. The patient received adjuvant radiotherapy and, at the time of writing, had no evidence of disease recurrence 3 years after surgery. The technical advantages of robotic surgery were remarkable for the safe dissection of the mediastinal structures, notably the superior poles of the thymus. 
Three-dimensional vision and traction through the use of grasping forceps on the robot's left arm, combined with the ability to perform precise movements within delicate cervical structures, contributed to the absence of vascular accidents or the need for surgical conversion in our study.

As shown in previous publications, resection of large thymic tumors by robotic surgery is safe and effective. ${ }^{(12,23)}$ In our study, large tumors (largest diameter: $12.5 \mathrm{~cm}$ ) were resected, which corroborates the hypothesis that size should not be considered an absolute contraindication to the method. Currently, the major limitation in cases of mediastinal lesions is the invasion of vascular structures, because the use of robots has not been proven safe in those cases.

Although robotic thoracic surgery has attracted great interest from many surgeons, its cost is still a limiting factor for the rapid spread of the technique. There are costs in several spheres, including the purchase of the robot, the maintenance and purchase of resources such as tweezers and disposable materials, and surgeon-specific training and certification to operate the robot. Although some studies show evidence of the economic advantage of robotic surgery, it is necessary for good perioperative outcomes, such as reduced complications and length of hospital stay, to contribute to the reduction of the total cost. ${ }^{(24)}$ This is directly related to the experience of the surgeon, who must overcome the learning curve and obtain better results. Future perspectives show the tendency for more institutions to believe in the evolution of technology and, thus, invest in minimally invasive robotic surgery, which contributes to the improvement of patient care. At the same time, thoracic surgeons are motivated to become specialized in reproducing results achieved in established medical centers.

We can conclude that robotic thoracic surgery is safe and feasible in the treatment of thymic tumors by presenting a low risk of complications and a short length of hospital stay. The learning curve and cost are still limiting factors for the spread of the technique, which has a promising future.

\section{REFERENCES}

1. Detterbeck FC, Zeeshan A. Thymoma: Current diagnosis and treatment. Chin Med J (Engl). 2013;126(11):2186-91.

2. Detterbeck FC, Parsons AM. Management of stage I and II thymoma Thorac Surg Clin. 2011;21(1):59-67, vi-vii. https://doi.org/10.1016/j. thorsurg.2010.08.001

3. Venuta F, Rendina EA, Klepetko W, Rocco G. Surgical management of stage III thymic tumors. Thorac Surg Clin. 2011;21(1):85-91, vii. https://doi.org/10.1016/j.thorsurg.2010.08.006

4. Wright CD. Stage IVA thymoma: patterns of spread and surgical management. Thorac Surg Clin. 2011;21(1):93-7, vii. https://doi org/10.1016/j.thorsurg.2010.08.007

5. Yim AP, Kay RL, Ho JK. Video-assisted thoracoscopic thymectomy for myasthenia gravis. Chest. 1995;108(5):1440-3. https://doi. org/10.1378/chest.108.5.1440

6. Ye B, Tantai JC, Ge XX, Li W, Feng J, Cheng M, et al. Surgical techniques for early-stage thymoma: video-assisted thoracoscopic thymectomy versus transsternal thymectomy. J Thorac Cardiovasc Surg. 2014;147(5):1599-603. https://doi.org/10.1016/j. jtcvs.2013.10.053

7. Herron DM, Marohn M: SAGES-MIRA Robotic Surgery Consensus Group.. A consensus document on robotic surgery. Surg Endosc. 2008;22(2):313-25; discussion 311-2. https://doi.org/10.1007/ s00464-007-9727-5

8. Kent M, Wang T, Whyte R, Curran T, Flores R, Gangadharan S. Open, video-assisted thoracic surgery, and robotic lobectomy: review of a national database. Ann Thorac Surg. 2014;97(1):236-42; discussion 242-4. https://doi.org/10.1016/j.athoracsur.2013.07.117

9. Terra RM. Thymic minimally invasive surgery: state of the art across the world: Central-South America. J Vis Surg. 2017;3:124. https://doi. org/10.21037/jovs.2017.07.13

10. Rueckert J, Swierzy M, Badakhshi $H$, Meisel A, Ismail M. Robotic-assisted thymectomy: surgical procedure and results. Thorac Cardiovasc Surg. 2015;63(3):194-200. https://doi org/10.1055/s-0035-1549007

11. Marulli G, Comacchio GM, Rea F. Robotic thymectomy. J Vis Surg 2017;3:68. https://doi.org/10.21037/jovs.2017.05.01

12. Wilshire $C L$, Vallières $E$, Shultz D, Aye RW, Farivar AS, Louie BE. Robotic Resection of $3 \mathrm{~cm}$ and Larger Thymomas Is Associated With Low Perioperative Morbidity and Mortality. Innovations (Phila) 2016;11(5):321-326. https://doi.org/10.1097/imi.0000000000000295

13. Huang J, Detterbeck FC, Wang Z, Loehrer PJ Sr. Standard outcome measures for thymic malignancies. J Thorac Oncol. 2010;5(12):201723. https://doi.org/10.1097/JTO.0b013e3181f13682

14. Huang J, Luo Q, Tan Q, Lin H, Qian L, Lin X. Initial experience of robot-assisted thoracoscopic surgery in China. Int J Med Robot. 2014;10(4):404-9. https://doi.org/10.1002/rcs.1589

15. Marulli G, Maessen J, Melfi F, Schmid TA, Keijzers M, Fanucchi O, et al. Multi-institutional European experience of robotic thymectomy for thymoma. Ann Cardiothorac Surg. 2016;5(1):18-25. https://doi. org/10.3978/j.issn.2225-319X.2015.08.13

16. Brown LM, Louie BE. Robot-Assisted Total Thymectomy: How | Teach It. Ann Thorac Surg. 2017;103(2):369-372. https://doi. org/10.1016/j.athoracsur.2016.11.058

17. Terra RM, Araujo PH, Lauricella LL, Campos JR, Costa HF, PegoFernandes PM. Robotic pulmonary lobectomy for lung cancer treatment: program implementation and initial experience. J Bras Pneumol. 2016;42(3):185-90. https://doi.org/10.1590/S180637562015000000212

18. Kang CH, Hwang Y, Lee HJ, Park IK, Kim YT. Robotic Thymectomy in Anterior Mediastinal Mass: Propensity Score Matching Study With Transsternal Thymectomy. Ann Thorac Surg. 2016;102(3):895-901. https://doi.org/10.1016/j.athoracsur.2016.03.084

19. Seong YW, Kang $\mathrm{CH}$, Choi JW, Kim HS, Jeon JH, Park IK, et al. Early clinical outcomes of robot-assisted surgery for anterior mediastinal mass: its superiority over a conventional sternotomy approach evaluated by propensity score matching. Eur J Cardiothorac Surg. 2014;45(3):e68 73; discussion e73. https://doi.org/10.1093/ejcts/ezt557

20. Ruffini E, Filosso PL, Guerrera F, Lausi $P$, Lyberis $P$, Oliaro A Optimal surgical approach to thymic malignancies: New trends challenging old dogmas. Lung Cancer. 2018;118:161-170. https://doi. org/10.1016/j.lungcan.2018.01.025

21. Bryant AS, Minnich DJ, Wei B, Cerfolio RJ. The incidence and management of postoperative chylothorax after pulmonary resection and thoracic mediastinal lymph node dissection. Ann Thorac Surg 2014;98(1):232-5; discussion 235-7. https://doi.org/10.1016/j. athoracsur.2014.03.003

22. Regnard JF, Magdeleinat $P$, Dromer $C$, Dulmet $E$, de Montpreville $V$ Levi JF, et al. Prognostic factors and long-term results after thymoma resection: a series of 307 patients. J Thorac Cardiovasc Surg. 1996;112(2):376-84. https://doi.org/10.1016/S0022-5223(96)70265-9

23. Kneuertz PJ, Kamel MK, Stiles BM, Lee BE, Rahouma M, Nasar A, etal Robotic Thymectomy Is Feasible for Large Thymomas: A PropensityMatched Comparison. Ann Thorac Surg. 2017;104(5):1673-1678. https://doi.org/10.1016/..athoracsur.2017.05.074

24. Novellis $P$, Bottoni $E$, Voulaz $E$, Cariboni U, Testori A, Bertolaccin $\mathrm{L}$, et al. Robotic surgery, video-assisted thoracic surgery, and open surgery for early stage lung cancer: comparison of costs and outcomes at a single institute. J Thorac Dis. 2018;10(2):790-798. https://doi.org/10.21037/jtd.2018.01.123 